\title{
RECRUITMENT AND PROMOTION IN SOME MEXICAN FIRMS
}

\section{Miguel Sanchez Padron*}

In Mexico we faced a much older industrial relations system than in either Senegal or Sri Lanka. Mexico had its first major strikes in 1906, and collective bargainings, (albeit in an embryonic form) were first conducted in 1912. The industrial relations practices which have grown up are, therefore, well institutionalized. Thus, we can say that there is a distinctive Mexican system of industrial relations. But there is also a good deal of variation within that framework. However, the whole spectrum of variations and its origins can not, at this stage, be dealt with; mainly because the analysis of the data is still incomplete.

I will therefore elaborate on two major aspects - recruitment, and promotion of manual workers - because they show differences resulting from one major source of variation - different patterns of union organization and strength of unions. The firms studied with the approximate numbers of manual workers employed are given below: a state owned railway carriage works 1,100 an American subsidiary car axle makers 400

a Mexican owner-managed textile firm 200

a Japanese-managed Japanese-Mexic an joint-ven ture electronics firm

a joint-stock textile company with Mexican shareholders

200

a Mexican-managed cement company with a single British owner of 49 per cent of capital

a brewery subsidiary of a large Mexican corporation

a steel-mill owned by the same corporation 1,000

\section{Recruitment}

I. Permanent and temporary workers

One basic feature of the work force of the firms included in this study, and in general of the industrial sector in Mexico, is the co-existence of a

\footnotetext{
* Miguel Sanchez Padron is a Research Officer at the Institute of Development Studies.
} 
permanent work force which has a very low turnover, with a constantly present but varying number of temporary workers with a high turnover.

Temporary workers are in general hired for short periods with no guarantee that the contract will be renewed, and most frequently perform unskilled jobs. In one or two firms, however (where the product market fluctuates more widely) a large number of temporary workers is employed at all times; they are hired for longer periods of employment and for more skilled jobs - the length of the contract justifies the learning of new skills. Although temporary work is always considered as a first step towards obtaining permanent employment the waiting period in the firms studied varies between two and six years, and though the law establishes that temporary workers should be given preference when permanent vacancies occur, temporary workers can rarely exercise this right if the permanent force is not increasing, because of the low turnover of permanent workers.

The majority of temporary workers of the firms studied tend to remain loyal to the firm for which they are working; that is, they do not search for jobs in other firms when they are idle because the more contracts a temporary worker has worked in a firm the more chances he will have of getting a permanent job.

The situation of permanent workers is quite different. The main characteristic of this section of the labour force is stability and security of employment. It is exceptionally rare for a worker to change his employment once he has obtained permanent status, though workers with general skills of a high level are slightly more inclined to be mobile. Whether recruited from temporary workers or otherwise, permanent workers are usually hired initially to fill the lowest grades of the promotion ladder (which, as we shall see, exists in all firms) and as vacancies occur up the ladder and/or the permanent work-force expands promotions to superior grades are granted. Quite apart from voluntary quits, permanent workers are strongly protected by the law and the unions against dismissal. Thus, turnover rates for permanent workers are exceptionally low (never higher than 7 per cent).

\section{Channels of recruitment and criteria}

It is in the Collective Agreements between the union and management 
(hereafter CA) that conditions and requisites of entry are specifically set out, the detail in which the matter is dealt with being highly correlated with the status and power of the union vis-à-vis the firm. The section on recruitment of a typical CA may read as follows:

1. union membership as an in dispensable condition for permanent and temporary workers to be hired;

2. establishment of the union as the sole supplier of labour, and period of time the union has to supply candidates to fill vacancies;

3. minimum age to enter employment (in most cases 16);

4. need for Certificate of Primary Education;

5. need for Health Certificate;

6. need for proof of the ability to perform the job.

The above clauses are not as a matter of principle always included in all CA, and even when they exist the ex tent to which recruitment is strictly carried out as set out in the CA also varies. However, irrespective of the different degrees of importance given to the above requisites, two generalizations can be made at this point: all firms laid particular emphasis on: (a) age; young workers (not more than in their late twenties) were preferred - those with enough working life left to justify the large retirement bonus; (b) education.

These regulations are designed to cover both bottom-of-the-ladder recruitment - the predominant form - and the (much rarer) recruitment of skilled workers who are slotted in to higher points in the promotion ladder. It is in the case of the latter that 'proof of ability' is most important and there is a wide variety in the means of regulating such proof. Frequently, too, there are provisions giving the union a longer grace period to supply candidates for this type of vacancy, though in effect (in the axle and electronics firm and in one limited case, in the carriage works) it is usually the firm rather than the union which actually finds candidates and the unions which subsequently give them membership, for there is a genuine shortage in Mexico of these highly skilled electronicians and mechanics, draughtsmen, toolmakers and turners.

But the main variation concerns the ef fective role of the union. The first clause (the union shop clause) is found wherever there is a CA, but 
there is considerable variation in the extent to which unions actually control recruitment both de facto and de jure; also in the ways in which they exercise such controls as they have. I shall attempt to indicate the spectrum of variations.

A. Right to supply labour by the union is established in the CA and the union fully exercises its right

This is the case in the carriage works, the two textile companies and the cement firm. The procedure in all these cases is for the firm to send a written request to the union for the amount and kind of workers needed. The union has a short and pre-established period to supply the workers needed by the firm, which the union in general does with no problem at all. Since the jobs to be filled by new entrants are almost always unskilled, there is no point in the firm questioning the suitability of any candidate to perform an unskilled job. Once the candidate proves he has the necessary requirements of health and education, the process of hiring is complete.

As can be seen, the firm is quite passive all along the process. On occasions the union has presented candidates in their late thirties and the firm has been forced to hire them despite a clear policy of preferring younger workers. It also shows the secondary ranking that personnel selection has in the eyes of these firms. This lack of screening of the candidate has particular importance if the permanent nature of the commitment of workers is taken into consideration, and the fact that it is from this starting pool of unskilled labour that the firm will obtain its skilled workers through a gradual process of promotion and on the job training.

How did the unions acquire such rights? From the union side the strength of union members' desire to be able to nominate their sons and cousins is easily explained by unemployment and the preciousness of permanent employment in the modern sector. But why some firms should have conceded this right rather than others is harder to say. What can be said is that (contrary to some of the hypotheses from which the research started) personnel selection has a secondary importance in the eyes of managers. I asked one personnel manager who showed some concern about this, if it was not possible for the firm 
to get the union to send more than one candidate for each post. 'The problem is that if it is the firm which puts the idea on the bargaining table in the CA revision, the union will ask for something in exchange, and a change in the recruitment process is not precisely one of our priorities - not enough to make us pay a price for it'. Which is not, however, to say that managers are entirely unconcerned, and the raising of educational qualifications has been one means they have adopted in an attempt to protect the quality of the work force. In several firms the requirement of primary school graduation had been introduced in the last ten years; others had in troduced the criterion of literacy.

\section{B. Recruitment in the hands of the union but firms control the hiring process}

This is the case in the axles and electronics firms. These two firms share certain common features, which are particularly relevant for their hiring policies; specifically, both firms are relatively new and have a continuously expanding permanent labour force, and in both cases members' control of the unions is weak; the union is dominated by outside professional 'leaders'. In these firms the prerogative of supplying labour is established in their respective CA in the same terms as in the CA of the firms of the previous group, but not all candidates sent by the union are hired - it is not only that some candidates are rejected but also that some of the workers actually hired are not union candidates. This applies not only to the hiring of temporary workers but also to the final admission of permanent workers which is in fact controlled by the firms through previous screening of all candidates by skill tests (in one case) or so-called probationary periods. ${ }^{1}$

Clearly the co-opted nature of the unions in these firms - the fact that they are less under the control of their members than of 'bosses' prepared to accommodate to managers' wishes - is one precondition for these arrangements. However, the firms' motives to intervene so actively in the hiring of their personnel, as rationalized by their respective personnel managers, are somewhat different. In the case of

1 The labour law forbids the signing of probationary contracts. The firm uses the round-about method of hiring workers for a fixed term contract of 28 days which is later transformed in to an 'indefinite length contract'. 
the (Japanese-owned) electronics firms, 'Most jobs in our firm require a manual ability that cannot be developed unless the worker possesses a minimum inborn dexterity'. In the case of the axles firm the answer was a straightforward one in terms of 'managerial prerogative' and the power balance. 'We consider the recruitment of personnel something that belongs to the firm and not to the union'.

\section{Recruitment totally controlled by the firm}

This group is made up of the steel-mill and brewery; both are parts of one of the few firms in Mexico in which unions do not have the right to supply labour. Furthermore, their CA also lacks mention of the other requisites for admission (education, age, etc.,) which generally are included in most CA in order that any changes in them should be subject to previous bargaining with the union. The only thing in this respect which they have in common with other firms is that workers must be accepted by the union before they can work in the firms at all. This in theory gives the union a power to veto any new worker, but in fact it is never used.

This difference in the institutional aspects of recruitment of this group of firms reflects two of the many features which make this group so clearly different from all the other firms studied: first, the group's concern with the quality of its labour force, and secondly the fact that the union, in these firms, though not controlled by outside bosses and apparently incorrupt, adopts a generally co-operative attitude to management, accepting as management prerogative a range of matters which unions in other firms seek to control.

The group's concern with the quality of the labour force shows itself in its systematic bureaucratized recruitment process in which education, a 'career philosophy', and what we might call an 'institutionalization of the personal contact' form the three basic pillars in the selection of candidates.

The stress on education ('the more the better') is nothing exceptional. However, what is important about these firms is that the reasons for using education as a screening device and the assumptions behind it have been worked out and neatly rationalized. Thus, the answer given 
by the Industrial Relations manager to the question: 'Is it not a waste to employ somebody with secondary education to sweep the floor?' was straightforward and came in a ready-made package wrapped with 'company philosophy'.

'In fact it is the opposite. Our policy is to recruit people into the lower levels so that later they can progress upwards. If a worker has not got sufficient education he will not be able to go up and this causes frustration. We feel that for the worker to have confidence in the company and identify himself with it, he must have career prospects. Despite what is said elsewhere, we think the Mexican first and foremost wants security. This self-actualization policy comes from the philosophy of the group which is that the profits of the group are the means to achieve the development of all the individuals who work in it'.

What we call the 'institutionalization of the personal contact' refers to the fact that candidates to be hired require three references from persons already working in the 'group'. Our suggestion that the latter is a potential source of favouritism was firmly rejected by all the managers with whom this matter was discussed. What they did, instead, was to praise what they considered the positive side of it: the responsibility that referees are expected to assume for the behaviour of the persons he has recommended. In fact, if there is any problem with a new employee one of his referees is told to talk to him and "put him on the right road again'. However, there is a rule which forbids relations to work in the same department.

\section{Promotion}

I. The structure of promotion ladders

All jobs in Mexican factories are arranged in to promotion ladders in one of two ways - either in a number of promotion chains in which each step is a specific job - furnace operator, first class welder, second class welder, etc. - or all the jobs in a factory are grouped into a definitive number of categories, with, say, category 4 including such diverse jobs as assistant electricians, painters, production operative first class, etc. The former system was found in the cement, carriage works, textile, steel-mill and brewery firms; the latter in the others: axles and electronics. Where the former system is used the various promotion chains may be based on any of the following: 
(a) a department in the functional organization of the firm, to be distinguished from the next though in many cases both coincide;

(b) an interrelated set of productive activities;

(c) a related skill.

In most cases, simplicity of operation and organization were the reasons given for having a single all-factory promotion ladder. However, an additional factor to be considered is clearly the technology, the production system used and the heterogeneity of skill requirements. In other words, where technology imposes a functional and clearly separate departmental organization where common skills are used, a promotion system composed of different promotion chains naturally develops. The important thing about this system is that there is a kind of continuity between the levels of each promotion ladder, either because all levels in the ladder require the same kind of skills but with increasing degrees of sophistication or, when skills are rather different, a standing-by-Nelly process provides the training links between the different levels. In the single promotion-ladder system, on the contrary, a considerable degree of discontinuity between levels or at some point in the ladder was the norm. For the purpose of illustration I will describe the promotion ladders of the carriage-works and cement firms.

The former firm has 18 different promotion ladders, each ladder with, in most cases, six levels. In general the different ladders grouped workers with the same kind of skill or job, so that there was a ladder for the foundry workers, another for welders, another for workers in the assembly line etc. There were cases, however, where workers with different skills were also on the same ladder because they were in the same department. An extreme case of this kind was the promotion ladder for panel-beaters; to climb a step up the ladder required such different skills that it was very difficult for them to be promoted. In fact, none of them has been able to rise to the next level, though many of them have the necessary seniority to do so. However, while I was in this firm management had promised to establish a new separate-promotion ladder for panel-beaters. A final striking feature of this firm's promotion system was that all equal levels in different promotion ladders, e.g. top level painters and tool-makers, earn the same wage, though a glaring difference in the skills and knowledge required by the highly skilled tool-makers and the painters, whose job was much less demanding, was not consistent with their equal wages. 
This becomes even more marked if the shortage of toolmakers in the labour market is taken in to consideration, a shortage which in turn is truly reflected in the high market wage for tool-makers. The only obvious rationale appeared to be to provide equal chances of advancement to workers in every department.

By contrast, the most significant feature of the promotion ladder in the cement firm was the marked discontinuity between almost all the levels of the ladder. The discontinuity is intrinsic to the technology used to obtain cement: the job of a kiln operative is different from the job of a crush operator and both in turn perform different jobs from the one performed by a laboratory assistant. Added to this is the isolation in which these jobs are performed, which further precudes any learning while working in another job. It is precisely the absence of a clear skill linkage between the different levels that makes this firm's promotion ladder the best prototype of a ladder set up, above more than anything else, to provide a career rather than to facilitate the process of training. While it is true that insiders, because of the general knowledge they have, may still be 'rationally' preferred over outsiders, the fact is that the norms regulating promotion reflected this discontinuity: paid training periods outside working hours were established to facilitate promotions to higher levels - the same training periods as would have been necessary to allow an outsider to learn the job.

The implications of the above description are quite indicative of the basic concerns the promotion structure incorporates in situations where, as in these firms, the union is fairly strong. In this sense, it represents a polar case of a spectrum which, ceteris paribus, gradually moves away from this promotion structure as the balance of power is tilted towards the side of management. The first of these concerns is to provide a 'career' for all workers. Hence, the job organization must link the different jobs in one way or another, even though, as in the case of the panel-beaters, the linkage is somewhat artificial. On the part of workers this concern for a career can be seen mainly as the result of the prevailing shortage of jobs elsewhere in the economy. Thus, workers tend to hold on to their jobs and consequently the only way to better themselves is by progressing within the firm. The second concern is with equality: everybody should have the same career options, which in the case of the carriage-works means having the same number of levels 
in each of the different promotion chains; and for complete equality, equal wages should be paid for the same levels. The latter equality, however, like the regulative device in granting promotions is probably more the consequence of the unrestricted entrenchment of seniority. In such a case, the common denominator between ladders becomes seniority (the very factor which promotion seems to reward most); skill differentials, as those existing between the painting and tool-making shop, are not taken into account when wages are set.

What remains to be analysed to complete the description of the structure of the promotion ladders is the degree to which the functions and tasks corresponding to each level or job in the ladder are established; in other words, to what extent the content of jobs is fixed and delimited. The importance of this aspect of the promotion ladder lies in the following two facts: first, this is the structural feature of the ladder which conditions most of the everyday allocation of labour within the firms. Here the question is not only whether a mechanic is justified in refusing to sweep his work-place but more importantly who is the welder or mechanic among the four categories of welders and mechanics who is entitled to accept or refuse a work-assignment - a compounded problem if overtime is involved. These were the kind of limitations that the principle of closely defined job descriptions, when it was really observed, imposed upon management. Second, it is only when the tasks that a job incumbent must perform are defined and delimited, that the principle of equal pay for equal work - a principle enshrined in the Mexican labour law - can be meaningful and operate effectively.

Only one of our firms, the Japanese-managed electronics firm, had overtly departed from this principle by promoting workers to higher-wage categories after the passing of promotion tests, irrespective of the jobs they were actually doing at the time. In other firms there were covert moves towards such a 'person-related' wage system through the ad hoc raising of the category of a job for no other reason than that the person had been doing it for a long time and was felt to 'deserve'. a promotion. But generally, the fixed-job-description and equal-pay-for-equal-work principles severely constrict management's ability to give discretionary promotions according to personal characteris tics. 
Probably the mere fact that the equal pay principle is institutionalized explains why it formed part of the frame of reference of both workers and managers. However, for management it acted mainly as a constraint in the allocation of labour. If the organization of jobs is such that the tasks corresponding to each category are delimited, the principle implies that any departure from the specified assignments should also entail differential payment in wages. The consequences of this are not only additional and cumbersome financial and administrative arrangements but also, as long as the worker is entitled to refuse an assignment, a restriction on management authority. The workers, for their part, were concerned to avoid 'deterioration of status' when there were minor or dirty additional tasks to be done, and to make sure that they could gain in pay when there were temporary absences to be filled in higher categories, or they were asked to do overtime on higher category tasks.

From a more general point of view workers were also concerned with restricting management authority. Since one of the most abundant and common exercises of managerial authority is to order tasks outside the customary or established assignments associated with a job, workers felt that by having the tasks corresponding to each job clearly delimited, managerial authority as such was also restricted. Thus, with the single exception of the electronics firm, the structure of the job organization was always designed on the basis that a specific set of tasks was alloted to each category or job. In other words, even when management was allowed to depart from the customary assignment of tasks with a certain degree of freedom, this was based on an unrestrained use of authority to bend the system and not on a structure of job organization designed, as in the electronics firm, to allow flexibility in the use of labour.

The full operation of the above job delimitation is enforced by the norms in the CA, which on the one hand establishes that under no circumstances will managers or supervisors order any worker to perform tasks that do not correspond to his category, and on the other oblige the firm to fill temporary absences with temporary promotions which in turn mean a temporary rise in wage. At the same time the delimitation of jobs also provides a general basis for the allocation of overtime; thus, even in the few remaining unregulated areas the system 
on the whole facilitates a substantial degree of workers' control over the allocation of labour.

The extent to which this control extends was illustrated in the maintenance department of the carriage works. Maintenance work, in the nature of the case, defies easy classification. The practice had developed that the supervisor in this department consulted with the higher category workers to decide what skill level a particular task required - i.e. which category of worker should do it. Consultation was especially necessary for overtime.

\section{Criteria or principles regulating promotion}

The Mexican Federal Labour Law, Article 159, has this to say about seniority promotion rights:

'When a vacancy occurs, either permanent or for a duration greater than thirty days, or when a new post is created, it shall be filled by the worker with the highest seniority in the next lower category of the relevant profession or trade. If there are two or more workers with the same seniority in competition for the post, it shall go to the more able. If the employer fulfils the obligations laid down in Article 132, Section VI (concerning the employers' duty to provide training facilities) the worker with a claim to the post shall be required to demonstrate that he possesses the knowledge and skill required to fill it'.

Although the law is unequivocal in establishing seniority as the regulating principle for promotion, in practice other elements always enter into the actual functioning of promotion systems. The collective agreements, by and large, faithfully mirror the spirit of the law; the two relevant principles are seniority and competence, and the various practices in different firms involve different weightings of these two factors and different operational interpretations of the concept of 'competence'. It will therefore be convenient to order the analysis of the different promotion systems around this dichotomy.

In the carriage works, textiles and cement, promotion follows the legal prescription, though not strictu senso in one respect. Whereas the law makes the need to give 'proof of knowledge' conditional on the employer providing opportunities for training, all the collective 
agreements stipulate the need for demonstrating competence whether courses are provided or not. However, as we shall see, this obligation has no great practical consequences.

In the three firms named, the worker with the highest seniority can claim priority in filling vacancies. In the carriage works and the cement firms promotion requires a theory test and a probationary period of 25 and 30 days respectively; while in the textile firm the worker has only to pass successfully through 15 days' probation. If the most senior worker fails the test or the probation, the next senior worker becomes eligible and so on down the line. Once again, as with recruitment, the employer's ability to influence the selection of candidates is minimal. It is not surprising that workers should seek to achieve this. We have already seen how, in a labour-surplus situation, the principal aspiration of the worker centres on his security and his possibilities of a career within the enterprise; the acceptance of the seniority principle gives the best assurance of fulfilling these aspirations automatically and without favour of the employer.

But the point to stress is how well, in these firms, they have succeeded - to the point that the actual functioning of the system tends to legitimate the idea that seniority alone guarantees promotion. In the first place, the way in which seniority is treated in the collective agreement rein forces the importance granted to it. The rights of seniority, declaims the carriage works agreement, 'and of promotion by seniority, are the exclusive property of the workers and as such are absolutely inviolable vis-à-vis the enterprise, the union or the workers themselves'. Such is the mystique of seniority, that inefficient workers have been said to go along cheerfully to the (written) tests for promotion, confident that their seniority gave them the 'right' to promotion. Secondly, the bureaucratic regulation surrounding promotion clearly restricts the ability of managers to influence the outcome; what is more, given the time-consuming nature of the procedures for set lling disputes, it is often more convenient for managers to arrive at a private agreement with union leaders than to stick to the letter of the rules' insistence on competence. Hence, when a candidate fails his test or his probationary period, union leaders argue, and often with success, that his seniority merits his being given a second chance - or that he simply be given the promotion anyway. The firm in any case is often in no legal position to take a hard line since it does not 
have the training courses which the law requires as a condition for insisting on tests of competence.

The extent to which the job structure and the seniority system combined limit the managers' control over the allocation of labour was graphically shown in some instances of promotion to cover temporary absences in the carriage works. Sometimes the worker next in line of seniority was not in reality competent to do the higher category job but in recognition of his right (tests are not required for temporary promotion) he would be given the pay of the higher post while some more able worker further down the seniority line was actually sent to do the job - and he also, of course, was paid at the higher rate.

In marked contrast with the former groups, the order of priorities is reversed in the other enterprises; the axle firm, the steel firm, the brewery and the electronics firm. That is to say, promotion was not given to the most senior worker once he had shown himself incompetent; rather it was given to the most 'competent' worker, with seniority relegated to a secondary place or ignored altogether. However, 'competent' is not entirely accurate: in the law competence is defined in terms of knowledge and skills necessary to do a job. In these firms, however, it was a rag-bag concept incorporating a variety of 'knowledge or other requirements' determined to serve the purposes of the enterprise, which was able to dominate and utilize the whole promotion system. Managers' control over the system is ensured first by the absence in the Collective Agreement of any guarantee of the union's right to share in the establishment of the criteria for promotion or in the taking of promotion decisions - a reflection of the greater weakness of the unions in these as compared with the last groups of establishment. Secondly, the fact that, in the electronics and axles firms at best, there was no clear functional relation between the job category and the work it required, permitted the granting of promotions with greater flexibility - and entirely at the discretion of the managers. Thus, whereas in the other firms, promotion, almost guaranteed by seniority, had become in Herzberg's terms a hygienic factor something that caused resentment if for any reason it was denied - in the latter firms it played a motivational role, a genuine carrot. 
A particular aspect of the above account must be emphasized. The crucial role of the unions in determining the differences between the firms studied has been consistent through all the other aspects of the research I have dealt with so far. This is important because it shows that some of the features which the Late Development hypothesis attributes to managers' initiative should be ascribed to union strength.

What is the source of this strength? The political role the unions play in the Mexican system can undoubtedly take us a long way in trying to answer this question. A typical activity under this role includes supporting the government against conservative industrialists. However, sometimes in their trade-union role, the unions verbally oppose the government, even adopting 'fight-to-the-last-ditch' rhetoric, i.e. threatening general strikes. In fact, no general strike, nor, for that matter, any major strike with serious implications for the economy, has taken place in the last fifteen years. Yet, the union warnings are taken very seriously by all the parties concerned. Given this ambiguity, that previous analyses of the unions leave one with a sense that something is missing should not be surprising. Yet a more comprehensive and historical account of the unions, in their industrial as well as their political role is essential for a better understanding of the Mexican industrial relations system.

A further stage of the analysis will be to establish what are the values of the above findings for policy. For example, given that turnover of permanent workers is fairly low, how relevant are the policy recommendations which implicitly attach a positive value to the 'proper' functioning of the labour market (especially the stress on mobility as the means of optimizing the allocation of labour). How relevant is it to talk about rigidities as a form of deviant anomaly, when those rigidities are, at least for some time, here to stay? What are the implications of the balkanization of one section of the labour market for employment generation policies? Given the active role of the unions in the recruitment process, can we afford to have reports on employment generation and practices which just do not mention them? 